\title{
Editorial: A Commentary on the Assessment and Analysis of "Culture-Content" in Basic Psychology Texts
}

Walt Lonner

Western Washington University, Bellingham,WA, walt.lonner@wwu.edu

Follow this and additional works at: https://scholarworks.gvsu.edu/orpc

Acknowledgments: My ongoing thanks to Elke Murdock for her continued interest in the cultural content of basic psychology texts and her contributions to this article. Our collaboration on this topic began in 1987 when she was a Fulbright student at Western Washington University. We met at the University of the Saar in 1985, when her country was still West Germany, and I was a Fulbright scholar. Elke went on, married, and along with her husband raised a family in Luxembourg. Several years ago, she re-entered graduate school and recently received her Ph.D. from the University of Luxembourg. I also want to thank Richard A. Griggs, Professor Emeritus, University of Florida, for various e-mail discussions we had about measuring cultural content in introductory psychology texts.

\section{Recommended Citation}

Lonner, W. (2016). Editorial: A Commentary on the Assessment and Analysis of "CultureContent" in Basic Psychology Texts. Online Readings in Psychology and Culture, 11(1). https://doi.org/10.9707/2307-0919.1144 


\title{
Editorial: A Commentary on the Assessment and Analysis of "Culture-Content" in Basic Psychology Texts
}

\begin{abstract}
This commentary focuses on one basic question: "How and to what extent do beginning university students in North America (United States as well as Canada) learn about culture's influence on behavior via introductory psychology texts that are almost always published in the U.S.?" An overarching question permeates the article: What objective methods have been used to find and evaluate the cultural content of beginning psychology texts? These questions are considered important in the teaching of psychology at the basic level and can influence the authors of texts that are central in psychology curricula in general and teaching crosscultural psychology in particular. In this unit, the earlier article by Lonner and Murdock (2012) and the recently uploaded article by Scott and Safdar (2016) focus on the cultural content of two types of basic texts in psychology. Respectively, they are the workhorse introductory text (IPT) and those that introduce social psychology (SPT). The main purpose of these two studies and seminal writings (Lonner, 1989; Rumple, 1988) was to assess and analyze the extent to which such texts in these areas contain information on culture and its proxies such as ethnicity and diversity.

\section{Creative Commons License} (c) (i) $\Theta$
\end{abstract}

This work is licensed under a Creative Commons Attribution-Noncommercial-No Derivative Works 3.0 License. 


\section{Introduction}

Analyses like those reported below can be useful to culture-oriented psychologists as well as many teachers of introductory and social psychology at the undergraduate level as these courses are typically taught in the United States, Canada, and a number of other Western countries. The twenty-first century has in fact been described as "the age of migration" (Castles \& Miller, 2009; United Nations Department of Economic and Social Affairs [DESA], 2009), and as a result, most student bodies have also become more heterogeneous. For several decades, cross-cultural psychologists have been advocates of shaping a global psychology (Berry, 2013; Lonner, 2015). Efforts in this area are the main reasons why the Journal of Cross-Cultural Psychology, the International Association for Cross-Cultural Psychology (IACCP), the Online Readings in Psychology and Culture (ORPC), and numerous related efforts have surfaced during the last fifty years. It is important for cultural scholars to know how, when, why, and by whom their work is finding its way into psychology curricula. Perhaps the best way to gauge the extent to which millions of naïve students are receiving initial academic exposure to the interface between psychology and culture is to assess the very texts that students are assigned to read and also to document how the authors and publishers of basic texts include culture as part of their instructional plan. ${ }^{1}$ That was the primary rationale for Elke Rumpel's 1987-88 master's thesis and the articles and studies that followed it (see below).

\section{Approaches to Assess the Cultural Content of Psychology Texts}

Teachers and researchers who have conducted objective and replicable content analyses of basic psychology texts, or plan to do so in the future, had (or have) several approaches from which to choose. Being objective and replicable, the options we include would be guided by a measure or metric that is easy to apply and explain, to share with others, and to publish. The characteristics of each option are summarized below.

\section{Word Count (WC)}

Simple and usually tedious to do, raters would identify "targets" or "hits" (descriptions and explanations of cultural material) and count the number of words used in each presentation.

1 In 1993, about four years after giving my IACCP presidential address (Lonner, 1989), I organized a three-day workshop at Western Washington University concerning the coverage of culture in IPTs. Participants included 10 psychology editors from major textbook publishers and 10 prominent culture-oriented psychologists. The primary purpose of the workshop was for the academics to advise and suggest to the psychology editors various ways they could improve the culture content of IPTs by informing their text authors of the recommendations. In the mid-1990s we noticed, in casual and occasional searching, that cultural coverage was markedly increasing. It would be presumptuous to suggest that the workshop was the only or even main factor accounting for this increase, but it certainly didn't hurt. 
Word counts could then be organized by, for example, chapter or topic and summarized in tabular form. Finally, total word count could be expressed as the fraction of "targeted" words by topic, chapter, or even in an entire text. Word counts alone would say very little about depth or breadth of coverage - only that $N$ number of words within target areas were counted. This option is rarely used.

\section{Whole Article Counts}

A variation of word count involves counting only the number of articles in journals, or even books and book chapters that focus to some extent on a specific target area or areas. For example, Lee, Rosen, and Burns (2013) documented, by decade, the "multicultural content" of a half-century of the American Psychological Association's (APA) Journal of Counseling Psychology (JCP) (1954-2009), the flagship journal in the field of counseling psychology. Analyzing the title and abstracts of all articles published during that period, Lee et al. (2013) tabulated the growth of including a wide range of "diversity" categories, such as gender, ethnicity, age, sexual orientation, and religion. It didn't matter how many words each article contained; a three-page article counted as much as a 30-page article. Their only goal was to gauge trends, over time, in JCP's reference to articles that focused on various dimensions of diversity.

Counting the number of citations in targeted areas, such as culture and diversity, by carefully sifting through the bibliographies of texts is another option. Unfortunately, this process could miss journal articles, books, and book chapters that focused on culture or diversity but was obscured by the titles of numerous documents. Another approach could involve finding the names of productive and well-known culture-oriented psychologists who are listed in the author index.

\section{Page Metric}

In numerous studies focusing on the content of IPTs, Richard Griggs and his colleagues have consistently used a page metric. For example, Griggs and Jackson (2013), in the update of a study done by Griggs, Jackson, Christopher and Marek (1999), examined the content, by topics, in 13 IPTs. Their analysis focused on traditional topics found in all IPTs (essentially entire chapters covering developmental, sensation and perception, social, etc.); "diversity" was included as a topic within what they called the "nontraditional" category. Their method, outlined in detail by Griggs and Jackson (2013, p. 164), guided their main goal: to determine the percentage of pages in IPTs devoted to 18 chapters (topics), including both the traditional and all-but-mandatory introductory and research methods chapters. The nontraditional category, labeled "Sex/Gender" (which included culture and diversity), was second to last in percentage of pages devoted to that category in the 13 texts. One might assume that sex and gender, not culture and its proxies, were the main topics in that category. To those looking for more coverage of diversity in a text, the results of the study might have been a little disappointing. The data did not report to what extent culture, specifically, was covered. 
Nevertheless, these studies, among others like them (such as Griggs, 2014), that are often published in the APA's Teaching of Psychology, have no doubt been useful to many teachers of psychology as they made decisions about text adoption.

\section{Grading Content for Depth and Breadth}

Elke Rumpel's (1988) master's thesis involving 35 IPTs and the follow-up study 20 years later that involved 40 IPTs were the first studies in this area to measure both the breadth and depth of cultural coverage in IPTs. Believing that such procedures as word count, citation count, or even a page metric, alone would not fully serve our purposes; a clear and transparent methodology to identify and document the cultural content systematically and consistently in the texts was deemed necessary. Although Rumpel (1988) did use word counts, pages counts, and other quantitative modes of assessment, her primary goal was to determine the extent to which culture and its proxies had winnowed their way into IPTs since the beginning of modern cross-cultural psychology in the mid-1960s. She also assumed that it may help guide psychology instructors in the selection of texts. She documented word count across two topical categories ${ }^{2}$ (which generally matched chapter titles) in 35 IPTs. As a master's thesis, she was obliged to undertake a number of other analyses, several of which were innovative.

Thirty-five years ago, such coverage was rather thin in psychology texts published in that era, but documentation was necessary. When Rumpel did her thesis, organized and institutionalized cross-cultural psychology was only about twenty-five years old. As the bellwether of the discipline, IPTs were, and arguably still are, the standard way to introduce hundreds of thousands of beginning students to the range and nature of psychological research, scholarship, and applications. It was perfectly logical for her to assess what was happening in basic psychology education with respect to culture by examining virtually all IPTs available at the time. I was her thesis advisor, and consequently had much more than usual interest in the project because her thesis was largely the basis of my IACCP presidential address in 1988 (Lonner, 1989).

Rumpel (now Murdock) and I developed another version of objective and replicable analysis in the mid-2000s. She agreed to join me in a 20-year update, or quasi-replication, of her thesis. As noted in Lonner and Murdock (2012), we built on the methodology of the 1988 study, and developed it further. Given the increase in volume, the word count methodology did not seem appropriate and we therefore developed the grading system as an efficient and replicable way to quantify the material. Because the target material was often "hidden" within the narrative text, the "page metric" method alone would not have served our purposes.

2 The most useful subjective evaluation of a text would be a comprehensive and full-fledged "book review" that could run several pages. One can occasionally read such reviews, but they are not very useful when comparing many texts for a specific course. In a miniscule way (using oneparagraph summary descriptions) Woolf, Michaels, Hulsizer, and McCarthy (2002) did this for 29 texts. 
In the initial study, it was easy to use word counts because of the limited coverage of culture in IPTs in the mid-1980s. Knowing that cultural coverage was far broader in IPTs twenty years later, we deployed the new method. Five gradations of the extent of culture content were used in measuring the "hits" that we identified by carefully sifting through the texts independently (both of us had copies of all 40 texts and we lived 6,000 miles apart): A (three or more pages), B (one or two pages), C (most of a single page), D (a paragraph containing 6-12 lines), and E (five lines or less). Scott and Safdar, authors of the second article in this unit, used the same procedure in their study of eight Canadian-based social psychology texts.

This method of scoring has several defensible characteristics. Importantly, it avoids using only a simple word (or page, or article) count for 40 texts, which, for all but a few, had large increases in cultural coverage. This made it possible to measure both the breadth and depth of coverage. Moreover, using only a word count or page count for a hit that received a grade of $\mathbf{A}$ under the new system would not capture the value of including photos ("a picture - even a small one - may indeed be worth a thousand words"), graphs, tables, illustrations, or other aids used to explain a cultural hit. Thus, an $\mathbf{A}$ grade tends to capture the depth of hits better (but certainly not completely - only detailed discussion would do that). A key advantage of this scoring method is that it provides information about the overall number of "hits" (breadth) and how the material is covered (depth) by providing the grading of the "hits." Regarding the potential problem of interrater reliability, we documented that the agreement in assigning letter-grade hits were very high, as the criteria for assigning the grades are very clear. The few discrepancies, none of which were more than a letter grade apart, were easily resolved. Also, the greater the coverage (A grades are the best examples), the more recent references it included and, perhaps obviously, the more informative was the textual discussion. Third, this method is highly replicable, thus providing the information needed to perform subsequent analyses of current and future IPTs, social psychology texts, or texts in any other field in psychology. Scott and Safdar's (2016) study supports the claim that this mode of analysis satisfies the intended goal of examining cultural coverage.

The most important and time-consuming part was to identify the cultural "hits" in each of the texts. To do this, we systematically screened the subject indices for pre-defined key terms, as well as the table of contents. We were guided by the principle of trying to determine the nature and scope of cultural coverage in psychology education for the purpose of monitoring its development in the discipline of psychology. All analyses in this area are welcome. Short of writing an exhaustive, detailed book report of each text, there may not be a perfect way to give psychology teachers all the information they need to make wise decisions.

Table 1 provides an example for the letter-grade approach. Extracted from Lonner and Murdock (2012), the top 10 texts by "total number hits" are shown. As can be seen, the texts differ in terms of depth of coverage - that is, if the coverage is in depth ("A"), at a medium level ("B and C"), or only briefly (" $D$ and E"). Taking depth of coverage into consideration, a "weighted total" is provided, and the change in position is indicated. Text No. 1 is characterized by covering topics in depth (four "A" grades), as well as breadth (highest 
overall number of absolute hits). When "depth" of coverage is taken into consideration, the ranking for the texts changes - except for the No. 1 position (see Table 1).

Table 1

Ranking Comparisons of Texts in Terms of Total No of "Hits" (Breadth) and Weighted No of "Hits (Depth) (extracted from Lonner \& Murdock, 2012)

\begin{tabular}{|c|c|c|c|c|c|c|c|c|c|}
\hline Authors & $\begin{array}{l}\text { No of } \\
\text { Pages }\end{array}$ & $\begin{array}{l}\text { No of } \\
\text { Chap- } \\
\text { ters. }\end{array}$ & $A$ & B & $\begin{array}{l}\text { Grading } \\
\text { C }\end{array}$ & $\mathrm{D}$ & $E$ & $\begin{array}{c}\text { Total } \\
\text { No of } \\
\text { "Hits" } \\
\text { (position) }\end{array}$ & $\begin{array}{l}\text { Weighted } \\
\text { Total No of } \\
\text { "Hits" } \\
\text { (position) }\end{array}$ \\
\hline $\begin{array}{l}\text { Myers }\left(2008,8^{\text {th }} \text { ed. }\right) \\
\text { Hockenbury \& }\end{array}$ & 772 & 18 & 4 & 5 & 11 & 27 & 25 & $72(1)$ & $152(1)$ \\
\hline $\begin{array}{l}\text { Hockenbury ( } 2006 \text {, } \\
4^{\text {th }} \text { ed.) }\end{array}$ & 670 & 15 & 2 & 9 & 13 & 15 & 19 & $58(2)$ & $134(4)$ \\
\hline $\begin{array}{l}\text { Kosslyn \& Rosenberg } \\
\left(2004,2^{\text {nd }} \text { ed.) }\right.\end{array}$ & 718 & 16 & 1 & 8 & 12 & 9 & 26 & $56(3)$ & $117(7)$ \\
\hline $\begin{array}{l}\text { Passer \& Smith } \\
\quad\left(2007,3^{\text {rd }} \text { ed. }\right)\end{array}$ & 655 & 16 & 1 & 9 & 22 & 18 & 4 & $54(4)$ & $147(2)$ \\
\hline Franzoi $\left(2007,3^{\text {rd }}\right.$ ed. $)$ & 643 & 16 & 1 & 9 & 20 & 17 & 5 & $52(5)$ & $143(3)$ \\
\hline $\begin{array}{l}\text { Sdorow \& Rickabaugh } \\
\quad\left(2006,6^{\text {th }} \text { ed.) }\right.\end{array}$ & 634 & 17 & 1 & 3 & 14 & 15 & 19 & $52(6)$ & $108(10)$ \\
\hline Santrock $\left(2005,7^{\text {th }}\right.$ ed.) & 697 & 16 & 0 & 7 & 10 & 17 & 16 & $50(7)$ & $108(11)$ \\
\hline $\begin{array}{l}\text { Lefton \& Brannon } \\
\quad\left(2006,9^{\text {th }} \text { ed.) }\right.\end{array}$ & 696 & 18 & 2 & 6 & 14 & 15 & 10 & $47(8)$ & $116(8)$ \\
\hline $\begin{array}{l}\text { Bernstein \& Nash } \\
\left(2008,4^{\text {th }} \text { ed.) }\right.\end{array}$ & 588 & 14 & 2 & 3 & 8 & 24 & 8 & $45(9)$ & $102(13)$ \\
\hline Feldman $\left(2008,8^{\text {th }}\right.$ ed.) & 621 & 17 & 2 & 6 & 8 & 13 & 15 & $44(10)$ & $99(14)$ \\
\hline
\end{tabular}

Note: Weighted total is calculated by summing up the weighted totals $(A \times 5+B \times 4+C \times 3+D \times 2+E \times 1)$

The grading approach is reminiscent of the bandwidth-fidelity dilemma in psychological testing. This involves a trade-off between a wide field of vision with little detail (breadth) and a narrow field of vision with great detail (depth). Does one want to know a lot about a little or a little about a lot? This is analogous to binoculars versus microscopes (Hogan \& Roberts, 1996).

The "rules" used in the rating system are clear cut and transparent. As Scott and Safdar (2016) did in their study, graduate or undergraduate students in psychology would likely do a good job in such a project after some training and practice. Getting the same texts to everyone would be a logistical matter. ${ }^{3}$

3 The 35 texts used in Rumple's (1987) thesis were not retained. However, the 40 texts used in the replication study were, and they will become part of the IACCP archives for future reference. Enterprising and youthful culture-oriented psychologists may be interested in conducting another replication in the years ahead. The 40 texts may be helpful. 


\section{Evaluating Methods}

We have described several ways of identifying culture content in IPTs and SPTs. It takes many hours and riveted dedication to find the "hits" in large textbooks that unequivocally focus on the target of culture. Note that the two quantification procedures have considerable common ground. The Griggs et al. (1999) "page metric" procedure is embedded in the letter grade option, wherein grades of $A, B$, and $C$ use a page metric (which tends to capture some depth), while grades of $D$ and $E$ use paragraphs and lines, respectively, for the much briefer and more numerous comments spread throughout most IPTs, which of course captures breadth.

These two procedures, and any others that seem reasonable, objective, and replicable are done in good faith with noble motives. Cultural content in IPTs, SPTs, and other basic texts in psychology is alive and well - albeit still a small fraction of more traditional content, which is still fed by the juggernaut of "Western" psychology (see Arnett, 2008; Christopher, Wendt, Merecek, \& Goodman, 2014; Cole, 2006; Henrich, Heine, \& Norenzayan, 2010; Lonner, 2015).

\section{Other Considerations}

In documenting the nature and scope of cultural coverage in basic psychology texts, there could be a number of other advantages to psychology education. Tabulating the frequency of, for example, specific authors, specific topics, books, journal citations, and benchmarks in the development of a field could aid in assessing the cultural content of basic texts. For example, Griggs and Christopher (in press) compiled a list of who's who in IPTs, as well as the most-cited IPTs, articles, and books. The only "pure" cross-cultural psychologist to make the list of top 33 cited psychologists was Harry Triandis. Paul Ekman made the list as well; his research on the facial expressions of emotions has been among the most top-cited bodies of culture-related research in IPTs for decades, and was nearly unanimously cited in Rumpel's thesis nearly thirty years ago (Triandis was also in the top 10 list). As noted earlier, such information could be amassed for culture-oriented psychologists and their areas of research. Rumpel (Murdock) did some of these things in her thesis, and for many, including myself, this information was helpful in academic instruction. Her research, the update study, and the Scott and Safdar (2016) analysis of eight Canada-oriented social psychology texts were informative with respect to gauging incremental inclusion of culture in widely used texts.

Some cautionary remarks are in order. First, the "modern movement" in cross-cultural psychology began in the mid-1960s (Lonner, 2013a, b). By 1980, this area of psychology had become increasingly influential, and by 2000 and beyond, interest in the cultural dimension in psychology exploded. Everyone seems to have "found" culture, and can now be characterized as an "intellectual diaspora gone global" (Lonner, 2015, p. 812). This diffusion has made it increasingly difficult to assess the extent to which current psychology students are being exposed to cross-cultural research and its applications. This difficulty certainly extends to basic psychology education and the ubiquitous IPTs, for they no longer are the only purveyors of culture and its influences. Fifty years ago it was quite easy to 
assess the scant coverage of culture in psychology. It is now a formidable challenge to document changes over time in the kind of coverage that unit 11 in the ORPC wishes to report and discuss. Psychology instructors have become increasingly aware of the importance of looking at the ways that culture affects everything that humans do, think, say, believe, value, and in the end, how they die. I share the time-honored view that the powers of culture, like the powers of biology, should be part of a good psychology education (see Keith, 2012). There may never be an IPT that is truly considered to be universal. Nearly twenty years ago, it was predicted that cross-cultural psychology would have a strong influence on IPTs in the future (Cush \& Buskist, 1997). Both studies reported in this unit one concerned with IPTs, the other with SPTs - show that cultural coverage in contemporary texts is far more prevalent than 50 years ago, but it currently does not play a commanding role in contemporary IPTs. Psychology is a big field, and authors of beginning texts, and their publishers, must be prudent about how much space can be devoted to any single topic, method, or perspective in the field.

Second, the Lonner and Murdock (2012) study is somewhat dated. IPTs tend to have "shelf lives" of about three years. Most of the 40 texts included in that project were published in the mid-to late-2000s, and many of them have been revised once, if not twice, since then. Thus, caution is urged in using the results of that project to help select texts. The Scott and Safdar (2016) study involved social psychology texts that are somewhat more current, with 2012-2013 publication dates. However, the main pervasive issue remains the same: How, why, and to what extent do contemporary IPTs and SPTs include culture and its role in shaping nearly every aspect of human thought and behavior?

Curious about the cultural content of current IPTs (on average, published about five years after the Lonner and Murdock (2012) study), I had a cursory look at about 18 of them. (I had neither the time nor inclination - nor did Elke Murdock - to assess all of them; that would have required many dozens of hours of meticulous searching and "grading" of each entry in each text). However, a few observations are offered. Current IPTs, like their forerunners, are impressive in the ways that their authors and publishers package the incredible range of topics in psychology. In this era of colorful media extravaganzas, most of the texts are attractive (and expensive) visual treats. The way they are put together, including crisp and clever writing, remarkable photos, cartoons, tables, illustrations, ad infinitum, immediately invites attention. It is no wonder that introductory psychology continues to be among the most popular offerings on college campuses in North America.

With so much to cover in an expanding field of study, it is not surprising that the coverage of culture continues to be fairly shallow in the typical IPT of about 500-600 pages. It is also no surprise that the coverage of culture in Canadian-based social psychology texts is relatively more pronounced. One must remember that the bulk of research in cross-cultural psychology draws more from social psychology than from any other area. The good news is that all of the SPTs and nearly all of the IPTs give some attention, in their introductory chapters, to the importance of culture in psychology (often subtitled the "sociocultural perspective" or "human diversity"), or describe it in sections with titles such as "psychological subfields." In my cursory examination (and loose application of our A-E grading system), there appears to be slightly more As, Bs, and Cs (depth), and perhaps a slight increase in 
Ds and Es (breadth) in current IPTs. As found in the Lonner and Murdock (2012) study, topics such as Individualism-Collectivism, values, and the cultural construction of the self, seem to receive more attention than other topics. Slightly disheartening news - at least to a dedicated cross-cultural psychologist - is that it is quite rare to see any accurate summaries or histories of the cross-cultural movement. Some IPTs even tend to suggest that crosscultural psychology is a very recent development in the discipline. Modern cross-cultural psychology is at least half a century old.

When choosing an IPT, it is recommended that the studies in this unit, or similar studies found elsewhere, be just one of several guides in selecting the "right" text. The genuinely culture-oriented instructor will almost certainly refer to outside sources or his or her own experience to inform students about contemporary culture-oriented psychology.

Thirdly, both reports in this unit focus almost entirely on IPTs that have been written by American and a few Canadian psychologists, primarily for large numbers of students from North America, especially from the United States. Some of the texts reach students in other countries via foreign affiliates of North American publishers. It would be valuable to learn how psychology students in European, South American, African, Asian, and Middle Eastern countries learn about the interface between culture and psychology in their institutions of higher learning. Reports on this topic would be welcome for possible publication in the ORPC as addenda to this commentary.

Finally, it is surprising that no IPT has ever been published that contained a full-blown chapter that focused entirely on culture and its myriad influences. If that should ever be done it would be a "Super A" effort, and would garner a page count to rival the other (on average) 18-20 chapters dealing with the usual traditional topics. The fact that such a culture-inclusive chapter has never appeared may be a bit upsetting to culture-oriented psychologists. Maybe the coverage of culture and its proxies has reached an asymptote in the IPT marketplace. Please refer to Lonner (1989, included in this unit) for a discussion of what I thought, nearly thirty years ago, might have helped explain the rather thin coverage of culture in IPTs.

However, globalization and internationalization have become critical parts of figuring out the fate of human existence. The work of cross-cultural psychologists and kindred-spirit scholars is here to stay in the form of an expanding cornucopia of books, journals, academic offerings, research grants, and conferences. The Online Readings in Psychology and Culture is doing its part in contributing to an increasingly inclusive and globalized psychology. Cole (2006) is right: Internationalism in psychology: We need it now more than ever.

\section{References}

Arnett, J. J. (2008). The neglected 95\%: Why American psychology needs to become less American. American Psychologist, 63(7), 602-614. http://dx.doi.org/10.1037/0003$\underline{066 X .63 .7 .602}$

Berry, J. W. (2013). Achieving a global psychology. Canadian Psychology, 54(1), 55-61. http://dx.doi.org/10.1037/a0031246 
Castles, S., \& Miller, M.J. (2009). The age of migration: International population movements in the modern world ( $4^{\text {th }}$ ed.). Basingstoke, England and New York, NY: PalgraveMacmillan and Guilford.

Christopher, J. C., Wendt, D. C., Merecek, J., \& Goodman, D. M. (2014). Critical cultural awareness: Contributions to a globalizing psychology. American Psychologist, 69(7), 645-655. http://dx.doi.org/10.1037/a0036851

Cole, M. (2006). Internationalism in psychology: We need it now more than ever. American Psychologist, 61(8), 904-917. http://dx.doi.org/10.1037/0003-066X.61.8.904

Cush, D. T., \& Buskist, W. (1997). Future of the introductory college textbook: A survey of college publishers. Teaching of Psychology, 24(2), 119-122. http://dx.doi.org/10.1207/s15328023top2402 7

Griggs, R. A. (2014). Topical coverage in introductory textbooks from the 1980s through the 2000s. Teaching of Psychology, 41(5), 5-10. http://dx.doi.org/10.1177/0098628313514171

Griggs, R. A., \& Christopher, A. N. (in press). Who's who in introductory psychology textbooks: A citation analysis. Redux. Teaching of Psychology.

Griggs, R. A., \& Jackson, S. L. (2013). Introductory psychology textbooks: An objective analysis update. Teaching of Psychology, 40(3), 163-168. http://dx.doi.org/10.1177/0098628313487455

Griggs, R. A., Jackson, S. L., Christopher, A. N., \& Marek, P. (1999). Introductory psychology textbooks: An objective analysis and update. Teaching of Psychology, 26(3), 182-189. http://dx.doi.org/10.1207/S15328023TOP260304

Henrich, J., Heine, S. J., \& Norenzayan, A. (2010). The weirdest people in the world? Behavioral and Brain Sciences, 33(2-3), 61-83. http://dx.doi.org/10.1017/S0140525X0999152X

Hogan, J. E., \& Roberts, B. W. (1996). Issues and non-issues in the fidelity-bandwidth tradeoff. Journal of Organizational Behavior, 17(6), 627-637. http://dx.doi.org/10.1002/(SICI)1099-1379(199611)17:6<627::AIDJOB2828>3.0.CO;2-F

Keith, K. D. (2012). The culture of teaching and the teaching of culture. Psychology Learning and Teaching, 22, 316-325. http://dx.doi.org/10.2304/plat.2012.11.3.316

Lee, D. L., Rosen, A. D., \& Burns, V. (2013). Over a half-century encapsulated: A multicultural content analysis of the Journal of Counseling Psychology, 1954-2009. Journal of Counseling Psychology, 60(1), 154-161. http://dx.doi.org/10.1037/a0031002

Lonner, W. J. (1989). The introductory psychology text and cross-cultural psychology: Beyond Ekman, Whorf, and biased I.Q. tests. In D. Keats, D. Munro, \& L. Mann (Eds.), Heterogeneity in cross-cultural psychology (pp. 4-22). Lisse, The Netherlands: Swets and Zeitlinger.

Lonner, W. J. (2013a). Chronological benchmarks in cross-cultural psychology. Foreword to the encyclopedia of cross-cultural psychology. Online Readings in Psychology and Culture, 1(2), Article 1, 1-15. http://dx.doi.org/10.9707/2307-0919.1124

Lonner, W. J. (2013b). Foreword. In K. D. Keith (Ed.), The Encyclopedia of cross-cultural 
psychology (Vol. 1) (pp. xl-li). Chichester, United Kingdom: Wiley-Blackwell.

Lonner, W. J. (2015). Half a century of cross-cultural psychology: A grateful coda. American Psychologist, 70(8), 802-814. http://dx.doi.org/10.1037/a0039454

Lonner, W. J., \& Murdock, E. (2012). Introductory psychology texts and the inclusion of culture. Online Readings in Psychology and Culture, 11(1) Article 1, 1-17. http://dx.doi.org/10.9707/2307-0919.1115

Rumpel, E. (1988). Systematic analysis of the cultural content of introductory psychology textbooks. Unpublished master's thesis. Western Washington University, Bellingham, USA.

Scott, C., \& Safdar, S. (2016). The inclusion of culture in Canadian social psychology textbooks: A content analysis of introductory texts. Online Readings in Psychology and Culture, 11(1), Article 2, 1-17. http://dx.doi.org/10.9707/2307-0919.1141

United Nations Department of Economic and Social Affairs (DESA). (2009). International migration report 2009: A global assessment. Retrieved from http://www.un.org/esa/population/publications/migration/WorldMigrationReport2009. pdf

Woolf, L. M., Michael, R., Hulsizer, M. R., \& McCarthy, T. M. (2002). International psychology: A compendium of textbooks for selected courses evaluated for international content (2000 OTRP Instructional Research Award). Retrieved from http://www2.webster.edu/ hulsizer/Publications/inter-comp-2.pdf 